\title{
Methyl Guanine Isomer Distinction by Hydrogen / Deuterium Exchange Using a Fourier Transform Mass Spectrometer
}

\author{
Bobette D. Nourse, Robert L. Hettich, and Michelle V. Buchanan \\ Analytical Chemistry Division, Oak Ridge National Laboratory, Oak Ridge, Tennessee, USA
}

\begin{abstract}
Differentiation of the seven isomers of methyl guanine has been accomplished by monitoring gas-phase hydrogen,/deuterium $(\mathrm{H} / \mathrm{D})$ exchange reactions of the protonated molecular ions with deuterium oxide $\left(\mathrm{D}_{2} \mathrm{O}\right)$ in a Fourier transform mass spectrometer. In each case a distinctive reaction rate for the first $\mathrm{H} / \mathrm{D}$ exchange was observed, and exchanges of up to three deuterium atoms occurred with characteristic ion abundances that could be used to differentiate the isomers. $O^{6}$-Methyl guanine, for example, showed only one slow II/D exchange with $\mathrm{D}_{2} \mathrm{O}$, whereas 1-methyl guanine exchanged two hydrogen atoms at a significantly faster rate. On comparison of the possible resonance structures of each protonated isomer with the experimental information about the number and rate of $H / D$ exchanges observed, a reaction mechanism involving a concerted proton abstraction-deuterium cation donation was proposed. (7 Am Soc Mass Spectrom 1993, 4, 296-305)
\end{abstract}

$\mathrm{T}$ The primary basis for mutagenic/carcinogenic activities of alkylating agents is alkylation of deoxyribonucleic acid (DNA); therefore, numerous investigations have been devoted to studying the interactions of alkylating agents with DNA [1-4]. Nucleic acids are prime targets for chemical mutagens / carcinogens because of their numerous sites of reactivity [1, 5]; however, not all DNA modifications cause mutagenic/carcinogenic behavior. 7-Alkyldeoxyguanosine, for example, is an abundant product but is easily repaired biologically and does not result in basemispairing damage [6]. Minor alkylation products, such as $O^{6}$-alkyldeoxyguanosine and $O^{4}$-alkylthymidine $[6$, 7l, however, are not easily recognized and repaired and are important in terms of their effects on transcription and translation activities $[1,2,8]$. The major DNA mutation and the most biologically important alkylation product resulting from methylating agents such as $N$-methyl- $N$-nitrosourea [9] or $N$-methyl- $N^{\prime}$-nitrosoguanidine $[10]$, is $\mathrm{O}^{6}$-methyldeoxyguanosine, which mispairs with thymine during DNA replication and results in GCAT translation mutations $[1,8,11]$. Thus, in assessing potential for biological effects, it is important to be able to identify the adduct, the site of attachment of this adduct on the nucleic base, and the position of the modified base in an oligomer. Therefore, considerable attention has focused on the struc-

Address reprint requests to Robert L. Hettich, Analytical Chemistry Division, Oak Ridge National Laboratory, Oak Ridge, IN 37831-6120. tural characterization [12-17] and isomer differentiation $[13,18]$ of alkylated nucleotides, nucleosides, nucleic bases, DNA, and RNA.

Current methods for characterizing DNA adducts include 1) ${ }^{13} \mathrm{C}$-nuclear magnetic resonance [19], which provides detailed structural information but has limited sensitivity, 2) high performance liquid chromatography followed by fluorescence [20], electrochemical [21] and radiochemical [22] delection, and 3) thin-layer chromatography with ${ }^{32}$ P-postlabeling detection [23]. Fluorescence line-narrowing spectroscopy has also been used to provide high-resolution and trace-level detection of cellular fluorescent macromolecular damage (DNA adducts) [24]. Although most of these latter techniques are very sensitive, they are limited in the analysis of unknown adducts because some knowledge of the identity and/or properties of the adduct must be known prior to analysis.

Mass spectrometry also plays a major role in the characterization of biological compounds and can be used in the identification of unknown samples as well [25-28]. Because biomolecules such as nucleotides, nucleosides, and oligonucleotides, are polar, nonvolatile, thermally labile compounds, alternative methods to electron ionization must be used to examine these species by mass spectrometry $[16,29]$. Fast-atom bombardment (FAB) $[27,28,30]$, secondary-ion mass spectrometry [31], laser desorption-ionization [32a, 33], matrix-assisted laser desorption [34, 35], and electrospray ionization $[35,36]$ have been successfully applied to their analysis. 
Mass spectrometry is capable of not only detecting and measuring molecular weights of biomolecules, but can also be used to examine molecular structure in detail. The use of mass spectrometry for isomer distinction and structural characterization of modified DNA, RNA, oligonucleotides, nucleosides, nucleotides, and nucleic bases are active areas of current research $[12-18,31 \mathrm{c}, 32,37-39]$. For example, collision-activated dissociation (CAD) of the $[\mathrm{M}-\mathrm{H}]^{-}$ ions of various methyl guanosine isomers in a Fourier transform mass spectrometer (FTMS) has been used as a method for isomer differentiation [18]. Desorption chemical ionization tandem mass spectrometry (MS/MS) has been used to determine the site of methyl attachment for phosphate-alkylated nucleotides [14]. Sugar-ring methylation versus nucleic base methylation of guanosine could be distinguished using laser desorption-ionization Fourier transform mass spectrometry [32a]. Time-of-flight secondary-ion mass spectrometry has been used to differentiate $O^{2}$ and $\mathrm{O}^{4}$-alkylthymidines [31c]. Furthermore, benzo[a]pyrene adducts of nucleic bases and nucleosides can be resolved by FAB MS/MS [32b, c]. FAB MS/MS has also been used to distinguish positional isomers of deoxyribonucleosides [32d] and pyridine [32e] adducts of 7,12-dimethylbenz[a]anthracene to investigate the importance of radical cation activation versus a diol epoxide activation mechanism.

Recent investigations in this laboratory have used laser desorption-ionization FTMS together with CAD to characterize aminopolycyclic aromatic hydrocarbon adducts of guanine [38] and to differentiate methyl guanosine isomers under negative-ion CAD conditions [18]. CAD is not always successful for differentiating isomers, and alternative structural methods must be found. Development of site-selective ion-molecule reactions is important for studying isomers that are otherwise indistinguishable by CAD and for probing larger ions for which CAD is inefficient. For example, solution and gas-phase $H / D$ exchange reactions can be used, in combination with mass spectrometry, for structure and fragmentation mechanism elucidation [40, 41] and to count the number of labile hydrogens [42-45] in relatively small organic and biological molecules. In addition, $\mathrm{ND}_{3}, i-\mathrm{C}_{4} \mathrm{D}_{10}, \mathrm{D}_{2} \mathrm{O}$, and $\mathrm{CD}_{4}$ have been used as chemical ionization reagent gases to promote $\mathrm{H} / \mathrm{D}$ exchange in a high-pressure chemical ionization source for many organic and biological specics $[43,44]$. Furthermore, O perdeuterioglycerol/ $\mathrm{D}_{2} \mathrm{O}$ has been used as a FAB matrix to exchange labile hydrogens in a number of biological samples [42]. In a recent study, selective $1 \mathrm{H} / \mathrm{D}$ exchange reactions using $\mathrm{ND}_{3}$ and $\mathrm{CH}_{3} \mathrm{OD}$ as reagent gases provided isomeric differentiation of polyfunctional compounds [45]. Sites of protonation as well as collision-energy effects and an ion-molecule complex exchange mechanism were investigated. Various effects, including differences in proton affinities between the reagent gas and the analyte ions, werc noted to influence site-specific H/D exchange in these compounds [45]. In the present structural investigation, $\mathrm{H} / \mathrm{D}$ exchange reactions using $D_{2} \mathrm{O}$ reagent gas were studied under relatively low pressures $\left(10^{-6}\right.$ torr) in a Fourier transform mass spectrometer in an attempt to determine, and selectively differentiate, the site of methylation in seven methyl guanine isomers. In addition, sites of protonation and an $\mathrm{H} / \mathrm{D}$ exchange mechanism were also investigated.

\section{Experimental}

Experiments were performed with an Extrel FTMS 2000 Fourier transform mass spectrometer (3-T magnet) (Millipore Extrel FTMS, Madison, WI) equipped with a Quanta Ray DCR-11 pulsed Nd:YAG laser [46, 47]. Laser desorption-ionization was accomplished with $266-\mathrm{nm}$ radiation directed into the vacuum system and focused (area of approximately $0.5 \mathrm{~mm}^{2}$ ) onto a sample disk at an estimated power density of $10^{6}$ $\mathrm{W} / \mathrm{cm}^{2}$. The laser pulse width was $8 \mathrm{~ns}$, and the pulse rate was varied between 0.03 and $3.3 \mathrm{~Hz}$, depending on the ion-molecule reaction time (typical reaction times were $300 \mathrm{~ms}-35 \mathrm{~s}$ ).

The experiments were initiated by firing the laser to desorb and ionize the sample. Although a matrix was not necessary to observe the $[\mathrm{M}+\mathrm{H}]^{+}$ions of methyl guanine, a substantial increase in the amount of the protonated species was observed when the sample was mixed with a nicotinic acid matrix. The samples were prepared by mixing approximately $200 \mu \mathrm{g}$ of methyl guanine with a $5-\mu \mathrm{L}$ aliquot of aqueous nicotinic acid solution $\left(8 \times 10^{-2} \mathrm{M}\right)$. The sample/matrix mixture was dried on the stainless steel probe tip over an area of approximately $1.5 \mathrm{~cm}^{2}$, which was then inserted into the vacuum chamber. Approximately 10 laser shots could be taken (without probe rotation) before sample depletion, which corresponds to a sampling of $67 \mathrm{ng}$ ( 400 pmol) per laser shot. The amounts of sample used in this study are by no means indicative of the detection limits for the laser desorption-ionization FTMS experiment. Because the laser is focused to approximately $0.5 \mathrm{~mm}^{2}$ and the sample covers a region of 1.5 $\mathrm{cm}^{2}$ on the probe, most of the sample in this case is never exposed to the laser spot. Although a few picomoles of sample can be put on the probe and examined easily by this technique [38], the larger sample quantities used in this report are for convenience because the main objective of this study was to examine $\mathrm{H} / \mathrm{D}$ exchange reactions for the methyl guanine isomers.

The resulting laser-desorbed positive ions were trapped in the source side of the FTMS cell, with trapping plates continuously maintained at $2.0,2.5$, or $3.0 \mathrm{~V}$. The $[\mathrm{M}+\mathrm{H}]^{+}$ions were then isolated by applying selective radiofrequency pulses to the FTMS cell. These excitation events result in elimination, by collision into the FTMS cell plates, of the unwanted ions without disturbing the ions of interest, in this case $[\mathrm{M}+\mathrm{H}]^{+}$. 
The $[\mathrm{M}+\mathrm{H}]^{+}$ions were then allowed to react with $\mathrm{D}_{2} \mathrm{O}$, at a static pressure of $1.2 \times 10^{-6}$ torr for all isomers, for reaction times ranging from a few milliseconds up to $35 \mathrm{~s}$. A complete mass spectrum of the resulting ion-molecule product ions at several reaction times could be obtained by broad-band excitation $(0-2.66 \mathrm{MHz}$ at $2.5 \mathrm{kHz} / \mu \mathrm{s})$ and detection of the ion cyclotron signal. Signal averaging of 10-40 laser shots was performed prior to Fourier transformation to increase signal-to-noise and to obtain better spectra. The probe was rotated to a new position when sample depletion occurred. Mass resolutions of 400-1500 (full width at half-maximum) were obtained at this pressure, and were sufficient to resolve the product ions formed on reaction of $\left[\mathrm{M}+\mathrm{H}^{+}\right.$with $\mathrm{D}_{2} \mathrm{O}$.

The methylated guanine samples were obtained from Sigma Chemical Co. (St. Louis, MO) and Chemsym Science Laboratory (Lenexa, Kansas) and used without further purification; nicotinic acid and $\mathrm{D}_{2} \mathrm{O}$ ( 99.9 atom \%D) were obtained from Aldrich Chemical Co. (Milwaukee, WI).

\section{Results and Discussion}

Laser desorption-ionization of the isomers of methyl guanine (Figure 1) generated abundant protonated molecular ions, $[\mathrm{M}+\mathrm{H}]^{+}$, as well as fragment ions, adduct ions (including sodium and potassium adducts from surface contaminants), and matrix ions. The addition of a nicotinic acid matrix enhanced the production of the $[\mathrm{M}+\mathrm{H}]^{+}$ion signal in this study, as has been noted previously $[34,35,48]$. The data shown in Figure 2 include the mass spectra for the isolation and subsequent reaction of the protonated molecular ion of 7melhyl guanine ( $m / z$ 166) with $\mathrm{D}_{2} \mathrm{O}$ at four specific reaction times. Contributions to the $[M+D]^{+}$ion intensity, from ${ }^{13} \mathrm{C}$ of the $[\mathrm{M}+\mathrm{H}]^{+}$ion, were minimized by isolation of a single ion (i.e., $[\mathrm{M}+\mathrm{H}]^{+}$at $m / z$ 166) at unit mass resolution (as shown in the 3 -ms reaction time spectrum in Figure 2). Two H/D exchanges were observed, for protonated 7-methyl guanine, to give the $[\mathrm{M}+\mathrm{D}]^{+}$and $[\mathrm{M}+2 \mathrm{D}-\mathrm{H}]^{+}$ions $(m / z 167$ and 168).

A graph of the percent relative abundance of each ion with respect to the $\mathrm{H} / \mathrm{D}$ exchange reaction time with $\mathrm{D}_{2} \mathrm{O}$ for 7 -methyl guanine is shown in Figure 3. This graph is the most representative of the four experiments performed for this isomer, with uncertainties in the percent relative abundances of $\pm 5 \%$. The total number of $H / D$ exchanges observed could be obtained in less than $10 \mathrm{~s}$ reaction time (for all of the methyl guanine isomers); however, very long reaction times (up to $35 \mathrm{~s}$ in this case) were monitored to ensure complete reaction. The percent relative abundances of $m / z 166,167,168,169$, and 170 at $35 \mathrm{~s}$ reaction time were $15,45,39,0$, and 0 , respectively, which illustrates that the percent relative abundance of each ion changes very little after approximately $10 \mathrm{~s}$ reaction time.<smiles>Nc1nc2[nH]cnc2c(=O)[nH]1</smiles><smiles>COc1nc(N)nc2[nH]cnc12</smiles>

Guanine

O'-Methyl guanine<smiles>Cn1c(N)nc2[nH]cnc2c1=O</smiles>

1-Methyl guanine<smiles>Cn1cnc2nc(N)[nH]c(=O)c21</smiles><smiles>Cc1nc2[nH]cnc2c(=O)[nH]1</smiles><smiles>Cc1nc2c(=O)[nH]c(N)nc2[nH]1</smiles>

$N^{2}$-Methyl guanine

8-Methyl guanine<smiles>Cn1c(N)nc(=O)c2nc[nH]c21</smiles>

3-Methyl guanine<smiles>Nc1nc2nccnc2c(=O)[nH]1</smiles>

Figure 1. Molecular structures and numbering system for guanine and the isomers of methyl guanine.

The experimental results for a reaction of the 8methyl guanine $[\mathrm{M}+\mathrm{H}]^{+}$ion with $\mathrm{D}_{2} \mathrm{O}$ are shown in Figure 4. Reaction times of up to $30 \mathrm{~s}$ were monitored, but again no significant changes were observed after $10 \mathrm{~s}$. Note the dissimilarities between the 8-methyl
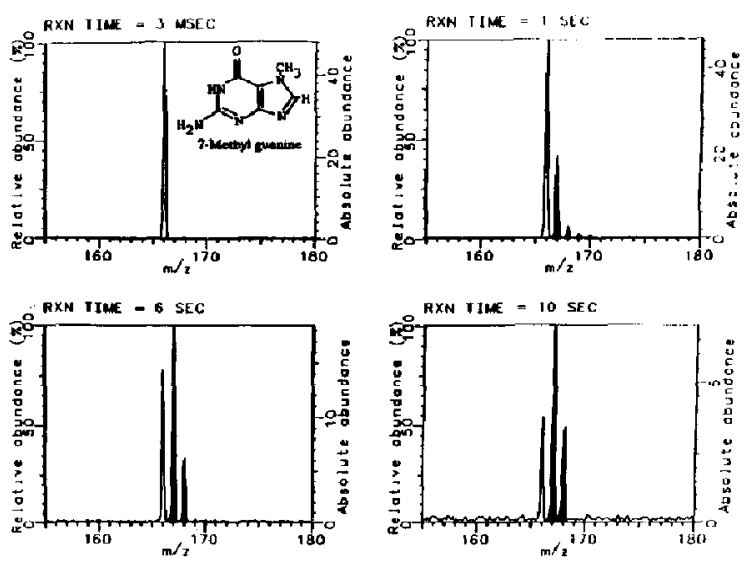

Figure 2. Mass spectra for the reaction of the $[\mathrm{M}+\mathrm{H}]^{+}$ion of 7-methyl guanine with $\mathrm{D}_{2} \mathrm{O}$ at varying reaction times. 


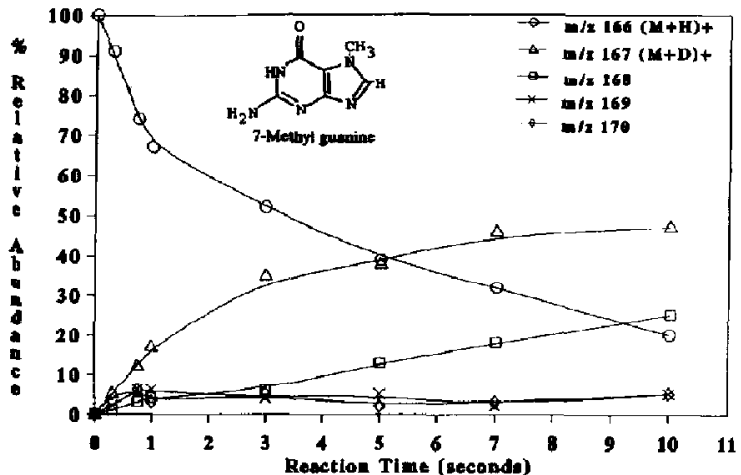

Figure 3. Percent relative abundance of the $[\mathrm{M}+\mathrm{H}]^{+}$and $[\mathrm{M}+n \mathrm{D}-(n-1) \mathrm{H}]^{+}$ions formed on reaction of the $\left[\mathrm{M}+\mathrm{H}^{+}\right.$ ion of 7 -methyl guanine with $\mathrm{D}_{2} \mathrm{O}$ at reaction times up to $10 \mathrm{~s}$.

guanine (see Figure 4) and 7-methyl guanine (see Figure 3) results. Three $\mathrm{H} / \mathrm{D}$ exchanges, to give $m / z 167$, 168 , and 169 , were predominantly observed for the reaction of $D_{2} \mathrm{O}$ with 8-methyl guanine; a fourth exrhange $(m / z 170)$ was seen at very low ion intensity. The first $\mathrm{H} / \mathrm{D}$ exchange $(\mathrm{m} / z 166 \rightarrow 167)$ occurred at a much faster rate for 8-methyl guanine (the ion signal ratio of $[\mathrm{M}+\mathrm{H}]^{+}$to $[\mathrm{M}+\mathrm{D}]^{+}$was $1: 1$ at approximately $400 \mathrm{~ms}$ ) than for 7 -methyl guanine (the ion signal ratio of $[M+H]^{+}$to $[M+D]^{+}$was $1: 1$ at approximately $5 \mathrm{~s}$ ). Furthermore, the total number of $\mathrm{H} / \mathrm{D}$ exchanges was different in each case (i.e., three $\mathrm{H} / \mathrm{D}$ exchanges were observed for 8-methyl guanine, whereas 7-methyl guanine showed predominantly two $\mathrm{H} / \mathrm{D}$ exchanges on reaction with $\mathrm{D}_{2} \mathrm{O}$ ).

\section{Site of Protonation}

The site of protonation for nucleic bases in both solution and gas phase has been a topic of question for a number of years [49-54]. Various studies and theoretical calculations suggest that the 7-position is the most probable site of protonation on guanine and that the

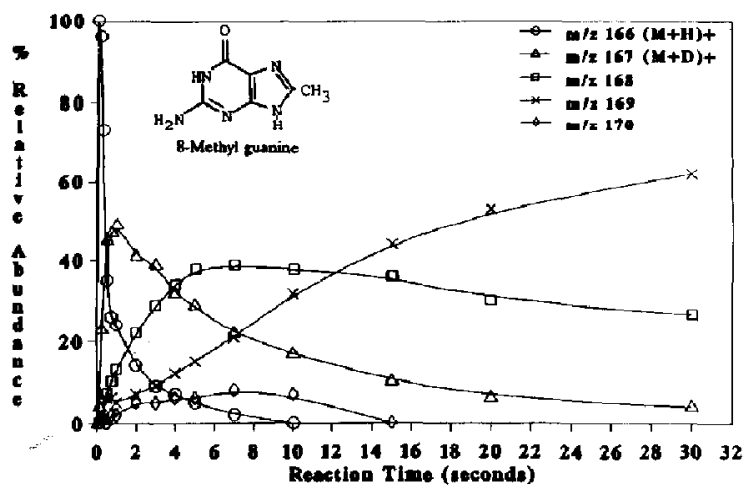

Figure 4. Percent relative abundance of the $[\mathrm{M}+\mathrm{H}]^{+}$and $[\mathrm{M}+n \mathrm{D}-(n-1) \mathrm{H}]^{+}$ions formed on reaction of the $[\mathrm{M}+\mathrm{H}]^{+}$ ion of 8-methyl guanine with $\mathrm{D}_{2} \mathrm{O}$ at reaction times up to $30 \mathrm{~s}$
$O^{6}$-position is the second most probable site (see Figure 1 for numbering system) [50-54]. Slight changes in resonance structures can dramatically alter the protonation site. For example, UV studies of pterins, which are quite similar in structure to guanine, indicate that the 3-position is the most probable protonation site, with the 7-position being the second most likely site of protonation for these compounds [55]. The site of protonation may change for the different methyl guanine isomers, although no studies have been performed to date to address this question. For this study, the most probable site of protonation was assumed to be at position 7 , with positions $O^{6}$ and 3 being the next most likely sites of protonation. The resonance structures for the three most probable protonation sites for guanine are shown in Scheme I. The keto form is the lowest energy configuration for most $\alpha$-hydroxy nitrogen heterocycles, although there are some exceptions (see ref 55 and references therein). Both the keto and enol resonance forms were considered for each isomer in this study, and we have chosen to illustrate the schemes and reaction mechanisms using the keto form throughout this report. Experimental evidence that supports the existence of the keto form for the methyl guanine isomers is presented later in Conclusion.

For the reaction of the $[\mathrm{M}+\mathrm{H}]^{+}$ion of guanine with $\mathrm{D}_{2} \mathrm{O}$, one could propose initial proton abstraction from the protonated site (or a hydrogen-substituted position in resonance with the site of protonation) followed by transfer of $\mathrm{D}^{+}$to guanine. The total theoretical number of acidic hydrogen atoms that could be abstracted can vary depending on the site of protonation (based on the possible resonance structures) from two (Scheme Ia) to five (Scheme Ic) in guanine. The number of $\mathrm{H} / \mathrm{D}$ exchanges and the rate of exchange

(a) 7-position protonation<smiles>C=c1[nH]c(N)nc2[n+]3c([nH]1)=C([NH+]=C3)C2=O</smiles>

(b) 3-position protonation<smiles>N=c1[nH]c(=O)c2nc[nH]c2c(=O)[nH]1</smiles>

(c) $\mathrm{O}^{6}$ - position protonation

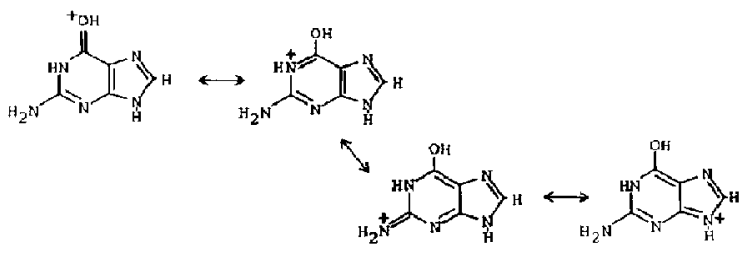

Scheme I 
can vary further when different sites are blocked by methyl attachment (see Figure 1 and Scheme I). Thus, there are two areas to consider in these experiments: (1) the basicity of a site(s) (proton affinity), which determines the initial site of protonation, and (2) the acidity of a site(s) (after the molecule is protonated), which influences the number of $H / D$ exchanges possible and the rate of $H / D$ exchange.

\section{$H / D$ Exchange Mechanism}

$\mathrm{H} / \mathrm{D}$ exchange usually occurs through a loosely bound complex formed between the analyte ion and a reagent molecule $\lceil 45,56]$. To describe the $\mathrm{H} / \mathrm{D}$ exchange reactions that can occur for the compounds in this study, consider the potential energy diagram for the reaction of protonated guanine with $\mathrm{D}_{2} \mathrm{O}$, as illustrated in Figure 5. A potential energy well is created on formation of an ion-molecule complex between protonated guanine and $\mathrm{D}_{2} \mathrm{O}\left([\mathrm{M}+\mathrm{H}]^{+} \cdots \mathrm{D}_{2} \mathrm{O}\right)$. In the simplest case, this complex is a proton-bound dimer of guanine and $\mathrm{D}_{2} \mathrm{O}$. The depth of this well is not precisely known, but it can be estimated to be substantially less than the proton affinity of water $(166.5 \mathrm{kcal} / \mathrm{mol}$ [57a]). Note that the structure of this ion-molecule complex may involve multiple hydrogen bonding between the protonated guanine and $\mathrm{D}_{2} \mathrm{O}$ and is discussed later. The energy acquired on formation of the ion-molecule complex can be used to initiate reactions such as proton transfer between the two species. Proton transfer from guanine to $\mathrm{D}_{2} \mathrm{O}$ and dissociation of the ionmolecule complex (to form $\mathrm{M}$ and $\mathrm{HD}_{2} \mathrm{O}^{+}$) cannot occur because this would be an endothermic reaction (the proton affinity of guanine is estimated to be between 220.6 and $227.4 \mathrm{kcal} / \mathrm{mol}$ [57], which is approximately $60 \mathrm{kcal} / \mathrm{mol}$ greater than the proton affinity of $\mathrm{D}_{2} \mathrm{O}$ ). Experimentally, $\mathrm{HD}_{2} \mathrm{O}^{+}$was not observed in the FT mass spectra. Proton transfer from guanine to $\mathrm{D}_{2} \mathrm{O}$ within the ion-molecule complex to form [M $\cdots$ $\mathrm{HD}_{2} \mathrm{O}^{+}$, although clearly a higher energy transition state, may be energetically allowable. This complex

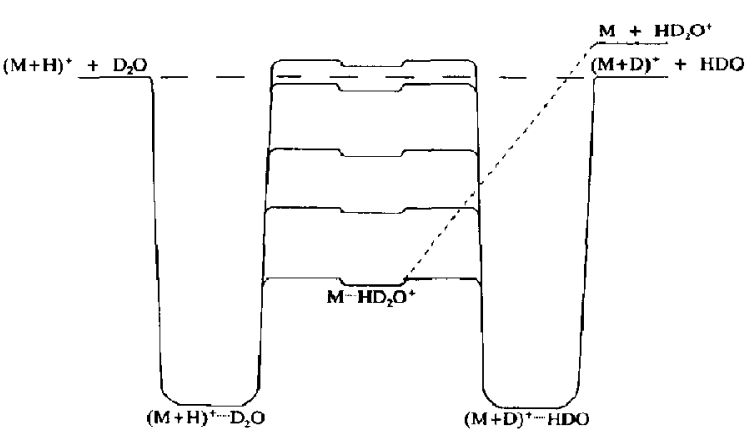

Figure 5. Potential energy diagram representing the ion-molecule reaction dynamics for the reaction of the protonated molecular ions of guanine with $\mathrm{D}_{2} \mathrm{O}$. The activation barriers and potential energy-well depths are estimated; exact values for the guanine system are not presently available. cannot directly dissociate; rather, it may transfer a deuterium cation back to guanine, instead of a proton, forming a new complex $\left([\mathrm{M}+\mathrm{L}]^{+} \cdots \mathrm{HLO}\right)$. 'I'his complex can either dissociate into $[\mathrm{M}+\mathrm{D}]^{+}$and HDO or undergo another exchange reaction. Note that the intermediate step, that of proton transfer from guanine to $\mathrm{D}_{2} \mathrm{O}$, may involve any one of several different protons, all of which have slightly different acidities. For example, simple abstraction of the initial proton (from the 7-position) may be the lowest energy process; however, abstraction of a proton from the 9-position would also alleviate the charge on guanine (Scheme Ia) and may be only slightly higher in energy. In fact, examination of possible resonance structures (Scheme I) indicates that the hydrogen atoms at positions $1, N^{2}, 3, O^{6}, 7$, and 9 can all be abstracted, depending on the site of protonation. Clearly, the energy available in the ion-molecule complex may prohibit abstraction of certain protons. The possibility of multiple sites for proton abstraction and $H / D$ exchange on guanine indicates that a manifold of transition energy states are available. This is represented in the energy diagram (Figure 5 ) by the different heights of the activation barriers, although precise values for the heights of the barriers are not known at the present time.

A more likely explanation for the transition state of the $H / D$ exchange process observed in our study may involve a concerted proton-abstraction/deuteriumattachment mechanism. Consider protonation on position 7 of guanine; the subsequent ion-molecule complex may involve multiple hydrogen bonding betweer the protonated guanine and $\mathrm{D}_{2} \mathrm{O}$. Because of the unique structure of guanine, formation of a seven-membered ring in which there is significant interaction between the $\mathrm{O}^{6}$ - and 7-positions [50] of protonated guanine with $\mathrm{D}_{2} \mathrm{O}$ (reaction 1) is quite likely, although other structures are certainly possible. This complex may then simultaneously abstract the proton from the 7 position and donate a deuterium cation $\left(\mathrm{D}^{+}\right)$to the

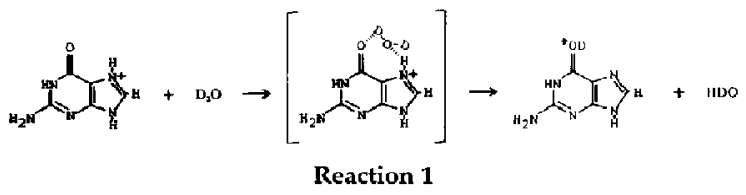

$O^{6}$-position of guanine. This would lower the activation energy needed for the transition step because complete proton abstraction from guanine would not be decoupled from reprotonation. In this case, the charge on the oxygen atom could then be resonantly distributed, as shown in Scheme Ic for protonated guanine, and further exchanges could occur.

\section{$H / D$ Exchange Results}

The reactions of the protonated methyl guanine isomers with $\mathrm{D}_{2} \mathrm{O}$ resulted in up to predominantly three 
$H / D$ exchanges. The maximum number and rate of $H / D$ exchange are influenced by the methyl attachment site and the number of acidic hydrogens that remain. The results illustrated in Figures 2-4 are representative of the experiments performed in this study. A summary of the $\mathrm{H} / \mathrm{D}$ exchange results for the reactions of the methyl guanine isomers with $\mathrm{D}_{2} \mathrm{O}$ is shown in Table 1. The second column represents the number of $\mathrm{H} / \mathrm{D}$ exchanges observed in each case. The third column shows the reaction time at which the ion signal ratio of $[\mathrm{M}+\mathrm{H}]^{+}$to $[\mathrm{M}+\mathrm{D}]^{+}$was $1: 1$, which can be qualitatively related to the rate of the first $H / D$ exchange process. Also note, as illustrated in Figures 3 and 4 , that the decay of the parent ion $\left([\mathrm{M}+\mathrm{H}]^{+}\right)$in each case is not a simple exponential. Although a quantitative investigation of the reaction rates of the isomers is beyond the scope of this report, this nonexponential decay may be attributed to differences in rates of $H / D$ exchange for different available sites within each isomer. Hence, this composite kinetic behavior is also a distinguishing feature for each isomer. In general, when second and third $H / D$ exchanges occurred, the rates of these exchanges followed the same trend as seen for the first exchange (i.e., a reaction with a faster first $H / D$ exchange rate also had a faster second $H / D$ exchange rate).

From the key results summarized in Table 1, a number of observations were made. With the exception of 1- and 9-methyl guanine, complete isomer differentiation could be made either by comparison of the number of exchanges observed, the rate of the first $\mathrm{H} / \mathrm{D}$ exchange, or a combination of both. For example, both 1- and 7-methyl guanine showed predominately two $H / D$ exchanges; however, the rates of exchange were significantly different (the ion signal ratios of

Table 1. H/D exchange results for the reactions of the $[\mathrm{M}+\mathrm{H}]^{+}$ions of the isomers of methyl guanine with $\mathrm{D}_{2} \mathrm{O}$

\begin{tabular}{|c|c|c|}
\hline Isomer & $\begin{array}{l}\text { Experimental } \\
\text { number of } \\
\text { H } \text { - D exchanges }\end{array}$ & $\begin{array}{c}\text { Reaction time } \\
\text { when }[M+H]^{+}:[M+D]^{+} \\
\text {is } 1: 1(\mathrm{~s})^{\mathrm{b}}\end{array}$ \\
\hline Guanine & 3 & $0.4 \pm 0.2$ \\
\hline $\begin{array}{l}\text { 1-Methyl- } \\
\text { guanine }\end{array}$ & 2 & $0.3 \pm 0.1$ \\
\hline $\begin{array}{c}N^{2} \text {-Methyl- } \\
\text { guanine }\end{array}$ & 3 & $0.7 \pm 0.1$ \\
\hline $\begin{array}{l}\text { 3-Methyl- } \\
\text { guanine }\end{array}$ & 1 & $2.5 \pm 1.0$ \\
\hline $\begin{array}{c}O^{6} \text {-Methyl- } \\
\text { guanine }\end{array}$ & 1 & $6.0 \pm 1.0$ \\
\hline $\begin{array}{l}\text { 7-Methyl- } \\
\text { guanine }\end{array}$ & 2 & $6.3 \pm 1.7$ \\
\hline $\begin{array}{l}\text { 8-Methyl- } \\
\text { guanine }\end{array}$ & 3 & $0.4 \pm 0.1$ \\
\hline $\begin{array}{l}\text { 9-Methyl- } \\
\text { guanine }\end{array}$ & 2 & $0.2 \pm 0.1$ \\
\hline
\end{tabular}

\footnotetext{
The number of $H / D$ exchanges with a percent relative abundance greater than $10 \%$; four exchanges were observed in each case (three for 3-methyl guanine) at long reaction times and very low abundance $\{10 \%$ relative abundance $\}$.

${ }^{b}$ Values presented are mean $\pm S D$
}

$[\mathrm{M}+\mathrm{H}]^{+}$to $[\mathrm{M}+\mathrm{D}]^{+}$were $1: 1$ at $0.3 \mathrm{~s}$ and $6.3 \mathrm{~s}$, respectively); consequently, isomer distinction was possible.

\section{8-Methyl Guanine}

Also noted in Table 1 , the number of $H / D$ excharges and the rate of exchange for guanine and 8-methyl guanine were the same. This observation suggests that a hydrogen atom attached to the carbon atom at position 8 in guanine and the other isomers of methyl guanine (see Figure 1) is not involved in the $H / D$ exchange processes in our experiments. The hydrogen atom at the 8-position has previously been reported to be unavailable for $\mathrm{H} / \mathrm{D}$ exchange in the gas phase [40a, 58]; the nonreactive behavior of position 8 toward $\mathrm{H} / \mathrm{D}$ exchange is believed to be due to the fact that this hydrogen atom is much less acidic than the other possible hydrogen atoms on guanine [ $40 \mathrm{a}, 58]$.

\section{$N^{2}$-Methyl Guanine}

Although complete $\mathrm{H} / \mathrm{D}$ exchange of the $N^{2}$ position hydrogen atoms is possible in solution-phase reactions $[18,42,58]$, our results suggest that these two hydrogen atoms (in guanine and in the isomers of methyl guanine) may not be involved in the gas-phase $H / D$ exchanges. This should not be too surprising because significant differences have been observed in the acidities and basicities of species in the gas phase versus solution phase, thus indicating that the solvent plays a significant role in the acid/base properties of compounds [41]. Theoretical calculations suggest that the $N^{2}$ - and C-8-positions are much less basic than the other positions [51]. In addition, comparison of proton affinities for numerous nitrogen-containing species [41, $57 \mathrm{a}]$, for example, aniline $(211.5 \mathrm{kcal} / \mathrm{mol}), \mathrm{CH}_{3} \mathrm{NH}_{2}$ (214.1 $\mathrm{kcal} / \mathrm{mol})$, pyridine $(220.4 \mathrm{kcal} / \mathrm{mol})$, and $\mathrm{CH}_{3} \mathrm{CH}=\mathrm{NC}_{2} \mathrm{H}_{5}(222.8 \mathrm{kcal} / \mathrm{mol})$, indicates that the proton affinity of the $N^{2}$ position may be relatively low; hence, protonation of the $N^{2}$-position should not occur in this case. Furthermore, our experimental evidence indicates that the $N^{2}$-position hydrogen atoms may not be as acidic in the gas phase as other hydrogen atoms in this molecule.

Evidence for the lack of $H / D$ exchange of the $N^{2}$ hydrogen atoms is the most obvious on comparison of the results of $N^{2}$-methyl guanine with guanine (Table 1); three exchanges werc observed in both cases. Because of methyl substitution of one of the $N^{2}$ hydrogen atoms, one less $H / D$ exchange than seen for guanine would be experted to occur for $N^{2}$-methyl guanine if the $N^{2}$-position hydrogen atom was involved in the $H / D$ exchange processes. The rate of the first $H / D$ exchange was similar to that of guanine, which is consistent with reaction 1 because the methyl substitution in $N^{2}$-methyl guanine should not inhibit the concerted $\mathrm{H} / \mathrm{D}$ exchange process. If the $N^{2}$-hydrogen atom is not involved in the exchange processes, a 
possible total of three $H / D$ exchanges would be expected, as illustrated for guanine in Scheme Ic.

\section{1- and 9-Methyl Guanine}

The results for 1- and 9-methyl guanine reveal that these two isomers showed one less $\mathrm{H} / \mathrm{D}$ exchange than guanine. In each case, a methyl group replaces an acidic hydrogen atom available for exchange. Therefore, the number of exchanges is expected to decrease by one, compared with that of guanine. The rate of the first $H / D$ exchange for 1 - and 9-methyl guanine was the same as that of guanine, within experimental uncertainty, which is attributed to the fact that positions 7 and $O^{6}$ are not blocked by a methyl substituent and are therefore open to $H / D$ exchange, as illustrated in reaction 1 for guanine. In these two cases, the available number of $\mathrm{H} / \mathrm{D}$ exchanges, following the first exchange, is then dictated by the resonance structures shown in Scheme Ic for guanine (with the exception of methyl-blocked positions 1 and 9, respectively). Two exchanges would be expected to occur in both cases (as shown in Scheme Ic for guanine), if the $N^{2}$-position hydrogen atoms are not involved in the $H$ / $D$ exchange processes.

\section{3-, $\mathrm{O}^{6}$ - and 7-Methyl Guanine}

In the cases of 3-, $\mathrm{O}^{6}-$, and 7-methyl guanine, resonance structural differences, compared with the other methyl guanine isomers (Figure 1), may influence the proton affinity of the molecules as well as basicities and acidities of various sites within the molecules.

For 7-methyl guanine, the proposed most probable site of protonation (7-position) is blocked by a methyl substituent; however, the next most probable site(s), the $\mathrm{O}^{6}$ - and 3-positions, are still available. Again, if the two $N^{2}$-position hydrogen atoms were not involved in the $H / D$ exchange processes, one would expect to observe two $H / D$ exchanges on protonation of either positions 3 or $O^{6}$ (Scheme II), and two exchanges were experimentally observed in each case (Table 1). The rate of the first $H / D$ exchange is believed to be much slower because the concerted $\mathrm{H} / \mathrm{D}$ exchange process,<smiles></smiles>
a

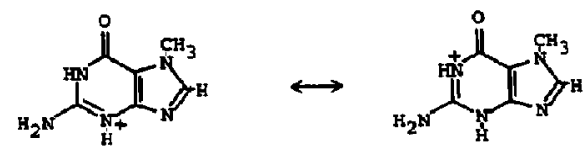

b illustrated in reaction 1 , would be severely inhibited for 7-methyl guanine because the methyl group is blocking the 7-position. In this particular case both proton abstraction and deuterium cation attachment are believed to occur at the site of protonation (or a site in resonance with the protonated site); resonance forms are illustrated in Scheme II for $\mathrm{O}^{6}$ - and 3-position protonation, respectively. Protonation at position 9 must also be considered because this position is very similar in structure and reactivity to the 7-position in guanine (Scheme Ia); however, on protonation of position 9, only one $H / D$ exchange would be expected to occur, whereas two $H / D$ exchanges were observed for 7-methyl guanine (Table 1).

The 3- and $O^{6}$-methyl guanine isomers were also relatively slow to exchange with $\mathrm{D}_{2} \mathrm{O}$ (Table 1), and predominantly one $\mathrm{H} / \mathrm{D}$ exchange was observed for each isomer. In each case, one likely site of protonation ( 3 or $O^{6}$ ) is blocked by methyl substitution; however, the most probable 7 -position site is still available. Once again, for 3- and $O^{6}$-methyl guanine, if the two $N^{2}$ position hydrogen atoms are not involved in the $\mathrm{H} / \mathrm{D}$ exchange processes, two exchanges would be expected to occur on protonation of either the 7-position (as shown for guanine in Scheme Ia) or on protonation of positions $O^{6}$ or 3 , respectively (Scheme III).

For protonated $O^{6}$-methyl guanine, the rate of the first $H / D$ exchange is believed to be slow because the concerted mechanism, illustrated in reaction 1 for guanine, would be substantially inhibited by the steric effect of the methyl group attached to the $0^{6}$-position. If this same concerted mechanism does take place, only one $\mathrm{H} / \mathrm{D}$ exchange would be expected to occur (reaction 2) and at a slower rate, as experimentally observed (Table 1). In this particular case, the 1-posi-

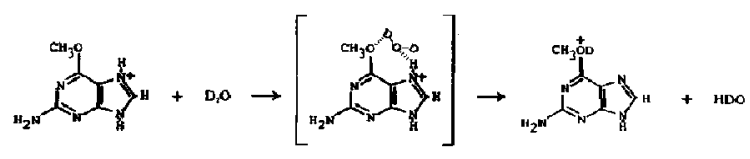

Reaction 2

tion does not have a hydrogen atom attached (see Figure 1); therefore, this position may be an additional possible site of protonation. Hence, a concerted reaction mechanism in which proton abstraction occurred
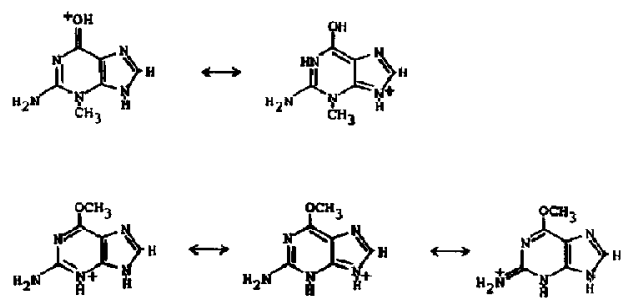
at position 1 and deuterium cation attachment occurred at the $O^{6}$-position (to give the same product ion as shown in reaction 2) may also be possible and would also result in only one overall $H$ /D exchange.

In the case of 3-methyl guanine, predominantly one $H / D$ exchange was observed at a faster rate than observed for $O^{6}$ - and 7-methyl guanine but at a slower rate than seen for the other isomers and guanine (Table 1). Both positions 7 and $O^{6}$ are unblocked and available for protonation and $\mathrm{H} / \mathrm{D}$ exchange. On protonation of positions 7 or $\mathrm{O}^{6}$, two $\mathrm{H} / \mathrm{D}$ exchanges would be expected [Schemes Ia (shown for guanine) and IIIa. respectively]; however, structural differences in this molecule (see Figure 1) may change the most probable site of protonation. For example, if position 1 were the most probable site of protonation in this case, one $H$ / $D$ exchange would be expected to occur (if the $N^{2}$-hydrogen atoms are not involved in the exchange processes), as illustrated in Scheme IV. The availability of the nitrogen atom at position 1 (which has no hydrogen atom substitution) opens up the possibility for a concerted $H / D$ exchange reaction (reaction 3 ), and if this reaction occurs, only one $H / D$

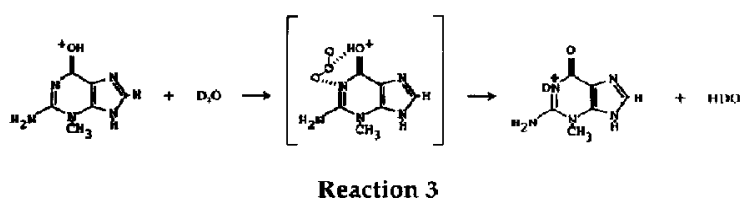

exchange would be possible. This concerted $\mathrm{H} / \mathrm{D}$ exchange mechanism explains the observation of a faster rate for the first $\mathrm{H} / \mathrm{D}$ exchange reaction (compared with $O^{6}$ - and 7-methyl guanine $H / D$ exchange). The reason that the reaction rate is different from that seen for guanine is attributed to the fact that reactions 1 and 3 are not identical concerted reactions.

\section{Negative Ion $H / D$ Exchange Reactions}

On laser desorption-ionization, negative ions are also formed for the different isomers of methyl guanine. On reaction of the $[\mathrm{M}-\mathrm{H}]^{-}$ions with $\mathrm{D}_{2} \mathrm{O}$, very little or no $\mathrm{H} / \mathrm{D}$ exchange was observed. Resonance structures for an $[\mathrm{M}-\mathrm{H}]^{-}$ion of guanine are represented in Scheme V. The 9-position in guanine contains a relatively acidic hydrogen atom. On CAD of negative ions of nucleosides and nucleotides [15, 32a, 40a, 48, 59], the glycosidic bonds (the sugar group is attached to<smiles>Cn1c(N)[nH+]c(=O)c2nc[nH]c21</smiles>

Scheme IV

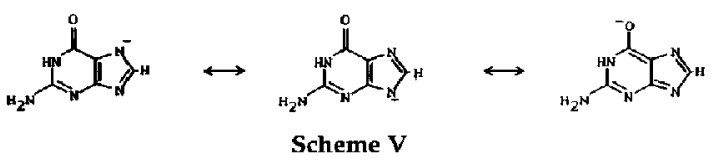

the 9-position in guanine) are often broken, resulting in the formation of negatively charged nucleic bases as fragmentation products [15, 32a, 59]. As illustrated in Scheme $\mathrm{V}$, the negative charge can be extensively delocalized; hence, one would not expect numerous $H$ /D exchanges with this very weak base.

\section{Methyl Guanosines}

Because laser desorption-ionization of nucleosides and nucleotides gives abundant nucleic base fragment ions $[48,59]$ that can be isolated using the FTMS, this technique of $\mathrm{H} / \mathrm{D}$ exchange to distinguish the position of methylation on guanine can be applied to such methylated compounds. $\mathrm{H} / \mathrm{D}$ exchange with $\mathrm{D}_{2} \mathrm{O}$ was examined in a preliminary investigation for the protonated nucleic bases formed from laser desorptionionization of 1-, $N^{2}$ - and 7-methyl guanosine, that is, [base - sugar $+(2)$ hydrogen] ${ }^{+}$, or $\mathrm{m} / \mathrm{z}$ 166. The number of $H / D$ exchanges observed for these fragment ions was the same as observed for the exchange reaction of $\mathrm{D}_{2} \mathrm{O}$ with the direct laser-desorbed ions of the methylated bases. The rates of the first $H / D$ exchange were the same, within experimental uncertainty, for 1and 7-methyl guanosine and slightly higher for $\mathrm{N}^{2}$ methyl guanosine at $1.5 \pm 0.5 \mathrm{~s}$. Because the structure of the $m / z 166$ ion should be the same whether the ion was formed from methyl guanine or methyl guanosine [15], one would expect the same number of exchanges and rate of exchange for ions of $m / z 166$, as experimentally observed.

\section{Conclusion}

$\mathrm{H} / \mathrm{D}$ exchange with $\mathrm{D}_{2} \mathrm{O}$ was used in conjunction with laser desorption-ionization FTMS to differentiate the isomers of methyl guanine. Although the $[\mathrm{M}-\mathrm{H}]^{-}$ ions showed very little $H / D$ exchange with $D_{2} O$, by comparison of the number of exchanges observed and /or the rate at which the positive ion signal ratio of $[\mathrm{M}+\mathrm{H}]^{+}$to $[\mathrm{M}+\mathrm{D}]^{+}$was $1: 1$, complete isomer distinction was possible, with the exception of 1- and 9-methyl guanine.

On comparison of the experimental results listed in Table 1, a number of observations can be summarized. The results suggest that under the gas-phase experimental conditions used here, (1) the hydrogen atoms at positions 8 and $N^{2}$ were not involved in $\mathrm{H} / \mathrm{D}$ exchange with $\mathrm{D}_{2} \mathrm{O}$; (2) hydrogen atoms at positions 1 and 9 were involved in $\mathrm{H} / \mathrm{D}$ exchange with $\mathrm{D}_{2} \mathrm{O}$; (3) a concerted $\mathrm{H} / \mathrm{D}$ exchange reaction mechanism (for the first $H / D$ exchange) involving positions 7 and $O^{6}$ 
explains the experimental data observed for guanine and 1-, $N^{2}-, O^{6}$-, 8- and 9-methyl guanine; (4) a concerted $\mathrm{H} / \mathrm{D}$ exchange reaction mechanism involving positions 1 and $O^{6}$ can explain the experimental data for 3- and $O^{6}$-methyl guanine; (5) both proton abstraction and deuterium cation attachment at the site of protonation explain the experimental results for 7 methyl guanine; and (6) the slower $H / D$ exchange reaction rates for 3-, $\mathrm{O}^{6}$ - and 7-methyl guanine can be attributed to structural differences that change the possible and probable sites of protonation and, hence, the mechanisms for exchange.

The mechanisms proposed for the $H / D$ exchange reactions in this report are shown using the keto form of guanine. This keto configuration is the lowest energy form for guanine (it may not necessarily be the lowest energy form for all of the methyl guanine isomers) and appears to fit the $\mathrm{H} / \mathrm{D}$ data better. The enol form, in which the hydrogen is located on the $O^{6}$-position rather than position 1 , is only slightly higher in energy than the keto form; however, this enol form for guanine would be very similar to the structure of $O^{6}$-methyl guanine, which is locked into the enol configuration. Experimentally, the number and the rate of the $H / D$ exchanges are significantly different for $O^{6}$.methyl guanine and guanine, suggesting that these two compounds may have substantially different resonance structures. On the basis of the number and the rate of the $H / D$ exchanges for all of the methyl guanine isomers, a concerted $H / D$ exchange reaction involving the $7-$ and $0^{6}$-positions of guanine was proposed. Further evidence supporting the keto structures comes from examination of the $\mathrm{H} / \mathrm{D}$ exchange reactions of $1-$ and 9-methyl guanine. The similarities of the $H / D$ exchange reactions for 1-methyl guanine, which must exist as the keto form, and 9-methyl guanine imply that these isomers have similar resonance structures. Although the participation of the enol forms of the methyl guanine isomers in the $\mathrm{H}$ / $\mathrm{D}$ exchange reactions cannot be absolutely ruled out, the experimental data best support the keto form for all of the isomers.

Examination of the number and rate of $H / D$ exchanges with other deuterium-labeled reagents, including $\mathrm{CD}_{3} \mathrm{Cl}, \mathrm{ND}_{3}$ and $\mathrm{CH}_{3} \mathrm{OD}$ (these include a range of proton affinities), may answer questions concerning why particular sites on protonated methyl guanine are prone to exchange and others are not. In addition, by choosing the appropriate reagent gas, one may be able to control the number of $\mathrm{H} / \mathrm{D}$ exchanges observed as well as the positions of the exchanges. $\mathrm{H} / \mathrm{D}$ exchange of the $N^{2}$-position hydrogen atoms, for example, does not occur in the reaction of methyl guanine with $\mathrm{D}_{2} \mathrm{O}$ under the experimental conditions used in these FTMS experiments; however, another reagent such as $\mathrm{ND}_{3}$ may yield favorable conditions for exchange. Information such as this may help to develop a quantitative understanding of the potential energy-well depths and barrier heights for the methyl guanine systems. Indeed, the efficiency of $\mathrm{H} / \mathrm{D}$ exchange has been noted to decrease as the difference in proton aftinity between the analyte and reagent gas was increased [45, 60]; this observation should also apply to the different available sites in a polyfunctional analyte [45].

Ion-molecule reactions, such as the above-reported $H / D$ exchange reactions using $D_{2} O$, may be superior to $\mathrm{CAD}$ experiments for structural characterization and elucidation of larger ionic species. CAD of large ions is difficult because of the large number of vibrational modes available to distribute the energy deposited; therefore, very large energies are required to fragment these ions. Ion-molecule reactions may be more useful than $\mathrm{CAD}$ as a structural characterization technique for large ions. Of course the complexity of the resulting ion-molecule spectrum increases with an increasing number of sites of reactivity; however, if an appropriate, site-selective reagent is found, interpretation of the ion-molecule spectra will be less difficult, and the challenge will be in creating, trapping and detecting very large ionic species.

\section{Acknowledgments}

Acknowledgment is given to the Office of Health and Environmental Research, U.S. Department of Energy under contract DE-AC05-84OR21400 with Martin Marietta Systems, Inc., and the Postgraduate Research Training Program under contract DEAC05-76OR00033 between the U.S. Department of Energy and Oak Ridge Associated Universities

\section{References}

1. Searle, C. E. Chemical Carcinogens, 2nd ed; American Chemical Society: Washington, DC, 1984

2. Singer, B.; Grunberger, D. Molecular Biolosy of Mutagens and Carcinogents; Plenum: New York, 1983.

3. Castellani, A. DNA Damage and Repair; Plenum: New York, 1989.

4. Basu, A. K.; Essigmann, J. M. Chem. Res. Toxicol. 1989, 1, 1.

5. Rao, T. K.; Lijinsky, W.; Epler, J. L. Genotoxicity of N-Nitroso Compounds; Plenum: New York, 1984.

6. Goth, R.; Rajewsky, M. F. Proc. Natl. Acad. Sci, USA 1974, 71 , 639

7. Singer, B. Cancer Res. 1986, 46, 4879

8. Loechler, E. L.; Green, C. L.; Essigmann, ]. M. Proc. Natl. Acad. Sci. USA 1984, 81, 6271

9. Kleihues, P.; Margison, G. P. I. Natl. Cancer Inst. 1974, 53 , 1839.

10. Lawley, P. D.; Thatcher, C. J. Biochem. I. 1970, 116, 693.

11. Silow, E. T.; Foote, K. S.; Mitra, S. Biochemistry 1984, 23, 4289

12. (a) Cooks, R. G.; O'Lear, J. R.; Chang, C.-J. J. Res, Nati, Bur. Stand. 1988, 93, 419; (b) Wood, J. M.; Hoke, S. H.; Chae, W.-G.; Chang, C.-J.: Cooks, R. C. Int. I. Mass Spentrom. Jon Processes 1991, 111, 381.

13. T'Tondeur, Y.; Moschel, R. C.; Dipple, A.; Koepke, S. R. Anal. Chem. 1986, 58, 1316.

14. Isern-Flecha, I.; Jiang, $X_{-}-Y_{. ;}$Pfleiderer, W.; Chae, W.-G.; Chang, Ching-jer; Cooks, R. G. Biomed. Environ. Mass Spectrom. 1987, 14, 17 .

15. Tomer, K. B.; Deinzer, M. L.; Gross, M. L. Anal. Chem. 1986, $58,2527$. 
16. McCloskey, J. A.; Crain, P. F. Int. T. Mass Spectrom. Ion Processes 1992, $118 / 119,593$.

17. Bryant, M. S.; Chiarelli, M. P.; Lay, J. O. J. Arr. Suc. Mass Spectrom. 1992, 3, 360.

18. Hettich, R. L. Biomed. Environ. Mass Spectrom. 1989, 18, 265.

19. Chang, C..-J.; I.ee, C..-G. Binchemistry 1981, 20, 2657.

20. Herron, D. C.; Shank, R. C. Anal. Biochem. 1979, 100, 58

21. Park, J.-W.; Cundy, K. C.; Ames, B. N. Carcinogenesis 1989, $10,827$.

22. Beranek, D. T.; Weis, C. C.; Swenson, D. H. Carcinogentesis 1980, $195,181$.

23. (a) Wilson, V. L.; Basu, A. K.; Essigmann, J. M.; Smith, R. A.; Harric, C. C. Cancer Res. 1988, 48, 2156; (b) Reddy, M. V.; Gupta, R. C.; Randerath, E; Randerath, K. Carcinogernesis 1984, 5, 231.

24. Jankowiak, R.; Small, G. J. Anal. Chem. 1989, 61, 1023A.

25. (a) McCloskey, J. A., Ed.; Mass Spectrometry, Vol. 193; Academic: New York, 1990; (b) Lawson, A. M., Ed.; Mass Spectrometry; Walter de Gruyter: New York, 1989.

26. Crain, P. F. Mass Spectrom. Rev, $1990,9,505$.

27. Slowikowski, D.; Schram, K. H. Nucleosides Nucleotides 1985, 4, 309 .

28. (a) Burlingame, A. L.; McCloskey J. A., Eds.; Biological Mass Spectrometry; Elsevier: Amsterdam, 1990; p 509; (b) McCloskey, J. A. In Mass Spectrometry in the Health and Life Sciences; Burlingame, A. L.; Castagnoli, N. Jr., Eds,; Elsevier: Amsterdam, 1985; p 521.

29. Standing, K. G.; Ens, W., Eds.; Methods and Mechanisms for Producing Ions From Large Molecules; Series B, Vol. 269; NATO ASI Series; Plenum: New York, 1991.

30. (a) Barber, M.; Bordoli, M.; Sedgwick, R. D. In Bĩological Mass Spectrometry; Morris, H. R., Ed.; Heyden and Sons: New

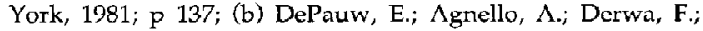
Mass Spectrom. Rev. 1991, 10, 283.

31. (a) Benninghoven, A.; Nieuhu is, E; Friese, T; Greifendorf, D.; Seffens, P. Org. Mass Spectrom. 1984, 19, 346; (b) Unger, S. E.; Schoen, A. E; Ashworth, D. J.; DaSilva, J.; Chang, C.-J.; Cooks, R. G. J. Org. Chem. 1981, 46, 4765; (c) Lafortune, F.; Beavis, R.; Schueler, B.; Tang, $\chi$.; Standing, K. G.; Westmore, J. B. Proceedungs of the 3bth ASMS Conferentce on Mass Spectrometry and Allied Topics; Denver, CO, May 1987; $\mathrm{p} 890$.

32. (a) McCrery, D. A.; Gross, M. L. Anal. Chim. Acta 1985, 178, 91; (b) Rogan, E. G.; Cavalieri, E. L.; Tibbels, S. R.; Cremonesi, P.; Warner, C. D.; Nagel, D. L.; Tomer, K. B.; Cerny, R. L.; Gross, M. L. J. Am. Chem. Soc. 1988, 110, 4023; (c) RamaKrishna, N. V. S.; Gao, F.; Padmavathi, N. S.; Cavalieri, E. L.; Rogan, E. G.; Cerny, R. L.; Gross, M. L. Chem, Res. Toxicol. 1992, 5, 293; (d) RamaKrishna, N. V. S.; Cavalieri, E. L.; Rugan, E. G.; Dolnikowski, G. G.; Cerny, R. L.; Gross, M. L.; Jeong, H.; Jankowiak, R.; Small, G. J. J. Am. Chem. Soc. 1992, 114, 1863; (e) Dolnikowski, G. G.; Cavalieri, E. L.; Gross, M. L. J. Am. Sac. Mass Spectrom. 1991, 2, 256.

33. Hillenkamp, $F_{4}$, Ehring, $H$. In Mass Spectrometry it the Biological Sciences: A Tutorial; Gross, M. I.., Ed.; Kluwer Academic Publishers: Dordrecht, The Netherlands, 1991.

34. Hillenkamp, F.; Karas, M.; Beavis, R. C; Chait, B. T. Anal. Chem. 1991, 63, 1193A

35. Karas, M; Hillenkamp, F. In Adzunces in Mass Spectrometry, vol. 9; Longevialle, P., Ed,; Heyden and Son: London, 1989; $p$ 416.
36. Fenn, J. B.; Mann, M.; Meng, C. K.; Wong, S. F.; Whitehouse, C. M. Mass Spectrom. Reo. 1990, 9, 37.

37. (a) Farmer, P. B; Bailey, E.; Gieen, J. A.; Leung, C. S; Manson, M. M. LARC Sci. Publ. 1991, 105, 71; (b) Giese, R. W.; Vouros, P. Environ. Sci. Res. 1990, 40, 211; (c) Saha, M.; Kreshach, G. M.; Giese, R. W.; Annan, R. S; Vouros, P. Biomed. Environ. Mass Spectrom. 1989, 18, 958; (d) Dizdaroglu, M. Methods Enzymol. 1990, 193, 842.

38. Hettich, R. L.; Buchanan, M. V. Int. I. Mass Spectrom. Ion Processes 1991, 111, 365.

39. McCloskey, J. A. Acc. Chem. Res. 1991, 24, 81.

40. (a) Hettich, R. L. Biomed. Enviran. Mass Spectrom. 1989, 18, 265; (b) Hettich, R. L.; Jacubson, K. B. Biomed. Mass Spectrom., in preparation.

41. Gas Phase Ion Chemistry, Vol. 2; Bowers, M. T., Ed.; Academic: New York, 1979; Chapter 12

42. (a) Guarini, A.; Guglielmetti, G.; Andriollo, N.; Vincenti, M. Anal. Chem. 1992, 64, 204; (b) Verma, S.; Pomerantz, S. C; Sethi, S. K.; McCloskey, J. A. Anal. Chem. 1986, 58, 2898.

43. (a) Hunt, D. F.; McEwen, C. N.; Upham, R. A. Tetrahedran Lett. 1971, 47, 4539; (b) Hunt, D. F.; McEwen, C. N.; Upham, R. H. Anal. Chem. 1972, 44, 1292.

44. Martinsen, D. P.; Buttril, S. E. Jr. Org. Mass Spectrom. 1976, 11, 762.

45. Ranasinghe, A.; Sethi, S. K.; Cooks, R. G. Org. Mass Spectrom. $1992,27,77$.

46. Buchanan, M. V., Ed.; Fourier Transform Mass Spectrometry; Evolution, Innovations and Applications; Am. Chem. Soc. Symposium Series 359; American Chemical Society: Washington, DC, 1987.

47. Lubman, D. M., Ed.; Lasers in Mass Spectrometry; Oxford Univ. Press: Oxford, 1990.

48. Hettich, R. L.; Buchanan, M. V. I. Am. Soc. Mass Spectrom. $1991,2,402$.

49. Lavery, R.; Pullman, A.; Pullman, B. Theor. Chim. Acta 1978, 50,67 .

50. Del Bene, J. E. J. Phys. Chem. 1983, 87, 367.

51. (a) Bonnaccorsi, R.; Scrocco, E; Tomasi, J.; Pullman, A. Theor. Chim. Actu 1975, 36, 339; (b) Bonnaccorsi, R.; Scrocen, F.; Tomasi, J.; Pullman, A. Theor. Chim. Acta 1972, $24,51$.

52. Izatt, R. M.; Christensen, J. J.; Rytting, J. H. Chem. Reo. 1971, $71,439$.

53. Lawley, P. D. Proc. Chem. Soc. Lottdon 1957, 290.

54. Fiskin, A. M.; Beer, M. Biochem. J. 1965, 96, 1289.

55. Pfleiderer, W. In Folates and Pterins, Vol. 2; Blakley, R. L.; Benkovic, 5. J., Eds.; Wiley: New York, 1985; Chapter 2.

56. (a) Squires, R. R.; Bierbaum, V. M.; Grabowski, J. J.; Depuy, C. H. I. Am. Chem. Soc, 1983, 105, 5185, and references therein; (b) Morton, T. H. Tetraltedron 1982, 38, 3195.

57. (a) Lias, S. G.; Bartmess, J. E.; Liebman, J. F.; Holmes, J. L.; Levine, R. D.; Mallard, W. G., Eds. J. Phys. Chem. Ref. Dala 1988, 17. Suppl. 1. (b) Greco, F.; Liguori, A.; Sindona, G.; Uccella, N. J. Am. Chem. Soc. 1990, 112, 9092.

58. Rice, J. M.; Dudek, G. O. I. Am. Chem. Soc. 1967, 89, 2719.

59. McCloskey, J. A. In Nucleosides, Nucleotides and their Biological Applications; Alderweireldt, F. C.; Esmans, E. L., Eds.; Univ. of Antwerp: Belgium, 1982; pp 47-67.

60. (a) Hunt, D. F.; Sethi, S. K. J. Am. Chem. Soc. 1980, 102, 6953; (b) Lias, S. G. J. Phys. Chemt. 1984, 88, 4401. 